\title{
MEDICINE UNDER SOCIALISM
}

\section{SOME OBSERVATIONS ON YUGOSLAVIA AND CHINA*}

\author{
Donna E. Parmelee ${ }^{1}$, Gail Henderson ${ }^{2}$ and Myron S. Cohen ${ }^{3}$ \\ ${ }^{1}$ Department of Sociology and Anthropology, Colgate University, Hamilton, NY 13346, ${ }^{2}$ Department of \\ Sociology, University of Michigan. Ann Arbor, MI 48109 and ${ }^{3}$ Department of Internal Medicine, \\ University of North Carolina, Chapel Hill, NC 27514, U.S.A.
}

\begin{abstract}
Based on fieldwork in Yugoslavia and China, we compare medicine in two societies which are attempting to construct their own unique paths to socialism. After a brief description of each country and its sociopolitical system. we sketch the broad outlines of the health care system which has evolved We then discuss certain constraints on achieving the socialist objectives of equality of access to health care and democratization of the patient-clinician relationship. In a concluding section, we summarize some of the similarities and differences in medicine under Yugoslav and Chinese socialism, respectiveiy.
\end{abstract}

\section{INTRODUCTION}

Although twentieth-century socialist revolutions have aroused much suspicion and. indeed, open hostility, they have also inspired hope among the world's disadvantaged and those who speak in their behalf. Among other things, socialism offers the promise of a more equitable distribution of goods and services, a promise which has often been realized, for example, in dramatically improved health delivery and health status.

There are few who would not be sympathetic to socialist objectives in the area of health, and encouraged by the progress which has been made in several countries of 'actually existing socialism' [1]. We would, however, take issue with such proponents of socialist medicine as Sigerist [2] and Navarro [3] who have rejected one set of intellectual blinders only to have substituted equally distorting lenses which focus most clearly on Potemkin villages. Likewise we would urge caution in drawing sharp distinctions between 'medicine under capitalism' and 'medicine under socialism' [4]. Such superficial reports and rigid dichotomies tend to obscure variations among socialist and among capitalist societies, as well as similarities between them. Thus, comparisons and

\footnotetext{
*A revised version of this paper was presented at the 1981 Annual Meeting of the American Sociological Association. Toronto. Canada.

D. E. Parmelee did research in the Socialist Federal Republic of Yugoslavia from October 1977-March 1980 supported in part by a grant from the International Research and Exchanges Board. Henderson and Cohen worked and studied in a provincial hospital in the Pcople's Republic of China from November 1979 to April 1980. under the auspices of the Section of Infectious Diseases at Yale University School of Medicine. the Yale-China Association and the University of Michigan Center for Chinese Studies. The support of these organizations is gratefully acknowledged. We would also like to thank our Yugoslav and Chinese hosts who facilitated this research. and Patricia Rieker and two anonymous readers for comments on an earlier draft of this paper. The views expressed are those of the authors.
}

evaluations of socialist and capitalist medicine seem to us premature without more careful and informed case studies, especially on 'medicine under socialism'.

The present paper is intended as a contribution to this end. Based on extended fieldwork in the Socialist Federal Republic of Yugoslavia and the People's Republic of China, we report on two aspects of medical care: access to care and the patient-clinician relationship. As Waitzkin and Waterman [5] stress, access to medical care and the doctor-patient relationship are generally stratified in capitalist socicty. On the one hand, different segments of the society have differential access to care. On the other hand, based on differential access to medical information, the doctor-patient relationship is characteristically hierarchical. Given claims that such stratification can be transcended under socialism, these would seem important areas to explore in societies which have experienced a socialist revolution.

Before turning to our case studies of Yugoslav and Chinese medicine, a comment on the approach we take is in order. In framing our description and analysis, we have been guided by a recent attempt by Rieker and Begun [6] to posit a 'social model of the illness process'. While intended as a model for organizing and teaching social science knowledge in medical schools, it also provides a useful framework for understanding how macro- and microsocial factors influence medical practice. As Rieker and Begun suggest, a distinctly social analysis of medical practice must take account of the wider social context (e.g. legal. political and economic institutions; health service organization) as well as social positions occupied by patients and clinicians (e.g. age, sex, occupation, class, geographic location). Applied to our present concerns, this model directs our attention first to the larger contexts of Yugoslav and Chinese socialism, and to the ways these societies have chosen to allocate and organize health resources. Once these macrosocial factors have been described, we can then examine access to care and the patient-clinician relationship in each society. It is at this point that we consider the influence of relevant patient and clinician social positions. 


\section{YLGOSLAVIA}

The sociopolitical context: self-managing socialism

The Socialist Federal Republic of Yugoslavia is a country of 22 million people located in the Balkan Peninsula of southeast Europe. It is composed of six republics (Bosnia-Herzegovina, Croatia, Macedonia, Montenegro, Serbia and Slovenia) and two autonomous provinces which form part of Serbia (Kosovo and Vojvodinal. The country is further divided into over 500 communes (comparable to districts or counties). With an average population of around 42,000 , the commune represents the basic unit of local government [7].

As a union of several South Slav national groups with different cultural heritages, religions, languages and alphabets and at different levels of social and economic development, socialist Yugoslavia emerged during the Second World War through a communistinspired national liberation struggle led by Josip Broz Tito. Notwithstanding persisting interregional variations in development, Tito's Yugoslavia has proven more successful than the pre-war monarchy in unifying these diverse groups. In large measure, this can be attributed to the unique form of sociopolitical and economic organization which has evolved under the general rubric of self-managing socialism. After breaking with the Soviet Union in 1948, Yugoslavia gradually moved from a highly centralized system of government and state planning to a much more decentralized arrangement giving greater formal decision-making power to the republics and communes (social self-government). Enterprises have gained considerable autonomy and are managed by workers themselves with decreasing state interference and increasing reliance on the market (worker self-management). Although the state [8] and political elites can and do intervene in guiding overall development of the country and influencing decision-making at all levels, there has been a genuine increase in the range of issues which are dealt with through direct negotiation among interested individuals and groups. Furthermore, opportunities for workers and citizens to participate in decision-making in their places of work and residence have expanded through creation of numerous participatory institutions (e.g. workers' councils, tenant councils, assemblies of users and providers of social services).

As measured by various indicators of economic and social development, Yugoslavia has made considerable progress. It has had one of the highest economic growth rates in the world. Per capita income in current prices increased from less than $\$ 100$ at the war's end to over $\$ 2000$ in $1977[9,10]$. Given the emphasis placed on industrialization and urbanization, the agrarian population declined from $63^{\circ}{ }_{0}$ in 1948 to $38^{\circ} \%$ in 1971 . With improvements in general standard of living, hygiene and medical care delivery, infant deaths per 1000 live births declined from over 116 in 1953 to 35 in 1977 (see Table 1 for selected resource, health services and health status indicators for Yugoslavia and China). However, as we have already suggested. the fruits of this progress are still spread unequally so that infant mortality, for example, ranges from 17 in the most developed republic (Slovenia) to over 73 in the least developed province (Kosovo) [7, 11].

\section{The organization and financing of health sertices}

These trends in the larger sociopolitical context have affected the organization and financing of health services in Yugoslavia. As in other socialist societies, health protection was immediately defined as a right and collective responsibility. Within limits set by the country's underdevelopment and priority given to industrialization, the new regime set about rebuilding and expanding the supply of health facilities and personnel decimated by the war. The number of hospital beds increased from less than 61,000 in 1952 to 130,000 in 1977 , while the number of physicians rose from around 6200 to over 28,000 in the same period $[12,13]$. Furthermore, health institutions were nationalized, with highly centralized administration and financing through social insurance contributions. Health workers became state employees, although physicians were initially permitted to practice privately after their regular working hours.

With moves towards decentralization and the evolution of self-managing socialism since the 1950s, a rather different system has emerged. Under policy guidelines set at the republic or federal level, the communes have the major responsibility for organizing and financing health services primarily through locally-derived and administered, mandatory health insurance contributions [14]. Health facilities are relatively autonomous $v i s-\dot{a}$-vis the state and have the status of socially-owned institutions managed (self-managed) by their employees and community representatives. Health workers are no longer state employees and are free to seek positions as they become available and are advertised. Remaining legalized private practice (involving less than $1^{\circ}$, of all physicians and dentists) is scheduled to be phased out by $1985[15,16]$.

For the Yugoslav who seeks medical care, the usual point of entry is the local health center. Staffed by general practitioners, dentists, nurses, laboratory workers and a limited number of specialists, the health center provides most outpatient care for residents in one or more communes, and integrates curative, preventive, educational and certain epidemiologi-

Table 1. Resources, health services and health status indicators for SFR Yugoslavia and PR China, 1977

\begin{tabular}{|c|c|c|c|c|c|c|c|}
\hline & $\begin{array}{l}\text { Population } \\
\quad(1000)\end{array}$ & $\begin{array}{l}\text { Area } \\
1000 \\
\mathrm{~km}^{2}\end{array}$ & $\begin{array}{c}\text { GNP } \\
\text { per } \\
\text { capita } \\
\text { US \$ }\end{array}$ & $\begin{array}{l}\text { Physicians } \\
\text { per } 100.000 \\
\text { population }\end{array}$ & $\begin{array}{l}\text { Hospital beds } \\
\text { per } 100,000 \\
\text { population }\end{array}$ & $\begin{array}{c}\text { Infant } \\
\text { mortality } \\
\text { rate* }\end{array}$ & $\begin{array}{l}\text { Life expectancy } \\
\text { at birth }\end{array}$ \\
\hline SFR Yugoslavia & 21,775 & 256 & 2094 & 131 & 603 & 35 & 69 \\
\hline PR China & 987.406 & 9597 & 378 & 33 & 185 & 65 & 64 \\
\hline
\end{tabular}

*Infant mortality rates are the death rates of infants under 1 year of age per 1000 live births. Source: [10]. 
cal services for its territory. The center is composed of general practice clinics dispersed throughout the commune, as well as separate clinics for industrial [17], school, and maternal and child health care, each with its own staff of appropriate specialists. For outlying rural areas, the health center often has branch stations with a full-time nurse or nurse-midwife and part-time physician.

For more specialized consultations and treatment on an outpatient basis, the general practitioner or other health center clinics make referrals to a polyclinic attached to a general hospital and staffed with a wide range of specialists and subspecialists. The patient normally returns to the local health center for prescriptions or hospital referral. As in most countries with a national health program, inpatient care is provided by full-time staffs in a relatively small number of large general and specialized hospitals.

To minimize expensive and unnecessary duplication of services, attempts have been made to integrate and coordinate the work of health institutions in a commune or over larger areas. On the one hand, there has been a tendency since the late 1950s for the health center, polyclinic and general hospital in a given commune to merge to form a medical center. On the other hand, there are efforts to coordinate the development of highly specialized services in a network of regional and republic-level hospitals, a goal, however, which often comes in conflict with the aspirations of autonomous local institutions.

Each of these individual health institutions is selfmanaged and self-financed. Employees of health institutions (like those of all socialized Yugoslav work organizations) participate in the management of their workplaces directly as members of the assembly of workers (all employees) and indirectly through their elected delegates in the workers' council. These selfmanagement bodies decide on the organization of work. hiring and firing, allocations of revenues and setting of pay scales, while day-to-day administration is left to the institution's director (usually a physician) and management board. To ensure representation of broader social interests, community delegates are included in self-management bodies. Nevertheless, health professionals retain a large measure of control over local institutions given their numerical advantage in these bodies and the tendency for community members to defer to professional expertise.

In contrast to China where considerable funding comes from the state budget. Yugoslav health institutions are largely self-financing. Not unlike various prepaid group practices in the United States, most health care costs and a portion of capital expenditures are financed through annual contracts negotiated prospectively with local health insurance associations. Other sources of funds include contracts with local work organizations for providing specific services to thcir employees. direct patient fees and government payments for certain groups (e.g. veterans, the indigent). On the basis of referenda, residents in one or more communes may also agree to make contributions for specific capital expansion projects.

Self-managing socialism has also shaped the organization of the local insurance associations. At one time part of the state administration, they are now autonomous organizations self-managed by assemb- lies composed of users and providers of services in a given commune. With the aid of a professional staff of administrators, the assembly is responsible for health planning and programming in the commune, negotiates contracts with provider institutions and decides on the rate of contributions to be collected as a payroll deduction from those employed in the socialized sector or as a tax or per capita payment from private farmers, craft workers and free professionals (e.g. writers, artists) [18]. Republic laws mandate a basic level of rights and bencfits which must be insured, although local associations may opt for more comprehensive coverage provided they agree to collect the necessary funds. Republic-level 'solidarity funds' assist communes unable to afford the basic level of services.

\section{Gaining access to care}

According to the Yugoslav Constitution, "everyone shall be entitled to health care" [19]. However in Yugoslavia (as in all other societies) this goal remains somewhat elusive. Although the country's commitment to national health insurance and to increasing the supply and improving the distribution of health personnel and facilities has made health care more accessible to the population, there are still financial and organizational barriers to obtaining care, in general, and higher quality care, in particular. Socialist aspirations to the contrary, there continues to be differential access to care depending on the specific "location' of the sick person in the social structure of Yugoslav society.

In this regard, decentralization of health administration and financing has had direct consequences for the problem of accessibility. While it can permit a closer fit between health service delivery and local needs and greater participation of users and providers in health care decision-making, there have been tradeoffs in the form of persisting inequalities in the availability and development of health services given the country's uneven economic development. Despite redistribution of a portion of locally-derived health monies via the solidarity funds, residents in wealthier and usually urban areas have easier access to higher quality care than do their counterparts in the poorer, mostly rural areas. Under such a decentralized arrangement, wealthier communes can generate a larger pool of health funds from which to finance more comprehensive care and more modern and betterequipped and staffed facilities.

Accessibility of care does not only depend on whether one lives in a more or less prosperous commune. Another factor is employment status. With industrialization as one of socialist Yugoslavia's key development objectives, greater priority has been given to providing mandatory health insurance coverage as well as special facilities (industrial outpatient clinics) for workers in the socialized sector. It was only after the late 1950 s that health insurance was extended to farmers (who have remained largely in the private sector) and to others privately employed (craft workers, professionals, private restaurant and hotel owners. etc.). Even then, benefits provided without payment at the point of delivery have usually been more comprehensive for those covered under workers' insurance with corresponding implications for easier access to care. However, the tendency 
towards equalization of benefits for workers and farmers during the 1970s is beginning to erase some of the differences in accessibility to care related solely to employment status.

Finally, ease of access is limited by what is commonly referred to as "bureaucracy". As in all societies with a national health program, there are certain formal procedures governing where and how a sick person obtains care. To illustrate, although a sick person in Yugoslavia is not necessarily assigned to a specific general practitioner, he/she is still required to have a referral ticket from the GP to obtain specialist care. Or, to keep health funds within the commune, insurance associations have made it more difficult for their beneficiaries to seek care outside the local service area (e.g. by requiring signatures from three physicians rather than one for referral outside the commune with full reimbursement). It should nevertheless be noted that various informal means are at times used to bypass such bureaucratic barriers and therefore enhance the accessibility of care. For example, it is not that uncommon for a Party member or someone else with 'connections' to obtain care wherever and whenever he or she chooses. Similarly, although illegal, bribes in the form of money or gifts may also give certain Yugoslavs an advantage over others in getting care.

\section{The patient-clinician relationshp}

Finally, we shall note a few features of the patientclinician relationship in the Yugoslav setting. In contrast to the Soviet Union and China, Yugoslavia has not attempted to train physician-substitutes or extenders, so that the important clinician to consider is the physician. While decentralization and selfmanagement have to some extent democratized decision-making between users and providers of services concerning health policy and planning issues, the relationship between patient and physician is still largely hierarchical. Patients continue to defer to the 'professional mystique' of physicians who have retained considerable prestige in Yugoslav society, notwithstanding low personal incomes relative to physicians in many capitalist societies or occasional campaigns to equalize their status with other workers [20]. Disproportionate recruitment into medical school of children of experts, managers and administrators only serves to reinforce this pattern [21].

However, this is not to say that the clinicians are in complete control in face-to-face interaction with patients. For one thing, the organization and financing of health care place certain limits on what is possible. For example, to control costs, some communal insurace associations have attempted to restrict drugs which are covered by insurance funds, with definite implications for physicians' prescribing habits. Patients as well are not entirely without bargaining power in the patient-clinician encounter. Thus, with a crowded waiting room of patients, it may be the easiest course of action for the physician to give in to patient demands for sick leave certification or specialist exams. In addition, the use of bribes and connections also tends to shape the clinicians' decisions apart from purely medical criteria.

At this point, we would make one further comment on the patient-clinician relationship in Yugoslavia. In our discussion thus far, we have interpreted the giving of money or gifts to clinicians as 'bribes', as something given by a patient to persuade or induce the clinician to do something the patient desires or simply as a means to get around the "system' more easily. However, based on our observations in Yugoslavia. they can also serve the function of a gratuity: that is, something given without claim or demand on the part of the patient. Thus, despite the fact that their care was covered by health insurance. it was not uncommon for patients to give something to physicians or other health workers out of gratitude for services provided. Whether this reflects some sort of underlying principle of reciprocity in the patient-clinician relationship or merely another way to insure against future health needs is something which requires further study.

\section{CHINA}

The sociopolitical context: democratic centralism

The Chinese revolution of 1949 brought unity and stability to a country torn by over a decade of war with Japan and 4 years of civil war between Nationalist and Communist forces. It also marked the culmination of a century of foreign aggression and internal conflict. The success of the peasant revolution promised radical improvement in the health and material condition of a population. devastated by war. famine and economic disaster.

The subsequent three decades have shown continuous. if occasionally erratic, economic and social development. Per capita income has risen from considerably below $\$ 100$ in the first half of the century [22] to $\$ 378$ in 1977 [10], although as in Yugoslavia, the pace of development has varied among different regions and between urban and rural areas. Improvements in the quality of life have included the eradication or substantial control of most communicable diseases [23] and a reported drop in infant mortality from over 200 per 1000 live births in 1949 [24] to approx. 65 in 1977 [10] (see Table 1). Furthermore, a complex referral system which reaches into the smallest villages has greatly enhanced the accessibility of health services. In contrast to Yugoslavia, however, China has not made the transition to an industrialized, urbanized society $(80 \%$ of the population live in the rural areas) [25]. Whether such a transition is feasible or desirable for an underdeveloped country with a population which will reach 1300 million by the year 2000 are dilemmas which still challenge the Communist leadership [26].

In this regard, the post-revolutionary period has been a time of political conflict over the appropriate path toward modernization. The tension between egalitarianism and material economic development has produced a rather 'zig-zag' pattern of national development policies. After 1949, the Chinese first adopted the Soviet model of highly centralized planning and administration. Priority was given to industrial development, much to the detriment of the agricultural sector. Mao's 1958 Great Leap Forward introduced decentralized administrative policies designed to promote industry and agriculture. Wellintentioned innovations in the organization of work and the use of non-material (moral) incentives to motivate work and political participation were ac- 
companied by poor planning and a dramatic decline in productivity in all sectors [26]. This was followed by a period of moderation and retrenchment (1962-66) in which emphasis was placed on economic recovery over socialist organizational objectives. Then, in response to what was viewed as a retreat from socialism. Mao launched the chaotic 10-year Cultural Revolution in 1966. Economic development was once again subordinated to egalitarianism. Ostensibly, the Cultural Revolution was Mao's effort to create a superstructure (i.e. educational, cultural and governmental institutions) more compatible with a socialist economic base. The severity of policies pursued to accomplish this resulted in such a decline in production and morale that those in power were overthrown after Mao's death in 1976. China's current leaders have since returned to more pragmatic, flexible economic policies.

The hasic socialist organizations in which all social, political and economic activities are conducted were gradually established during the first decade of Communist rule. In the countryside, however, the size of these collective work groups, as well as the basic level of accounting. have varied depending upon the particular policy in vogue at the national level. Soon after the 1949 Revolution. peasants were grouped into mutual aid teams for production purposes. Agricultural cooperatives were formed within five years, and by 1958, all of rural China was organized into large communes of approx. 16,000 people. Each commune is under the administration of the county government and divided into brigades of around 1000 people. Brigades. in turn, are divided into production teams (corresponding to one or more natural villages). These organizations of 100-200 persons have been the basic unit of work in the rural areas for the last 15 years. In the cities, people were assigned to state or collectivelyowned enterprises. and also to neighborhood organizations for the purposes of communication and control. In many cases, the work unit and neighborhood coincide as larger enterprises house workers in their own dormitories. Most business, service and commercial enterprises were socialized by 1958 [26].

Despite shifts in political winds, decision-making in China has for the most part remained consistent with the phrase, 'Democratic Centralism'. That is, planning proposals originate at the top and are circulated to appropriate lower levels for comment. with final decisions made by the central leadership. The implementation of decisions is left to local leaders who are responsible to higher levels of authority. While the Chinese urban work units and rural brigades correspond structurally to the Yugoslav self-governing communes. their degree of actual autonomy in decision-making is far more limited. However, this can facilitate smoother central planning and coordination of the society. in general, and health services. in particular.

\section{The organization and financing of health services}

In pre-revolutionary China, a small number of Western-style medical centers, largely under the auspices of foreign missionary or philanthropic organizations, provided services to the well-to-do population [27]. Most people. however. sought medical care from traditional practitioners or did without it. Since 1949. major efforts have been made to increase the accessibility of services to various sectors of the population. As a result of ideological and pragmatic policy decisions, traditional Chinese medicine has been integrated into the Western-style medical care system at every level. Furthermore, as in Yugoslavia, the evolution of the post-revolutionary health system in China has mirrored changing development policies.

Thus, during the 1950 s and, to a lesser extent, in the period following the Great Leap Forward, health service delivery was rather centralized and favored urban areas and industrial workers. In contrast, the Great Leap Forward and Cultural Revolution sought a more equitable distribution of health resources and produced experiments in the transfer of personnel and funds to the countryside to achieve this objective [24].

Today, lines of referral in both rural and urban areas are fairly standardized. For the rural population, a decentralized network of health centers at the brigade level represents the first line of health care. These centers are staffed by 'barefoot doctors', and aided by auxiliary health workers in the production teams. 'Barefoot doctors' are paramedics trained for at least 6 months to conduct fundamental preventive and educational health work, treat minor conditions and refer more complicated cases to outpatient and inpatient facilities at the commune level. Recently, their role has been re-evaluated [28] and new programs to upgrade their training and standardize the quality of care they dispense have been introduced [29]. The commune health facilities are staffed by physicians and other health personnel, and have departments for such specialities as medicine, surgery, obstetrics, gynecology and pediatrics [30]. When demed necessary, rural patients may be referred further to the better equipped and staffed county and district hospitals, or to designated urban referral hospitals. Transfer to urban hospitals is rare, but does seem to occur more commonly for rural residents who live close to urban areas or who are seriously ill [31]. In the cities, primary care is provided in neighborhood and work unit clinics and in district or other city hospital outpatient departments. Like brigade health centers in the countryside, urban neighborhood and work unit clinics are usually staffed by paramedics who make referrals to physicians in huspitals and medical centers. Work unit clinics in large factories or other enterprises may have physicians as well as paramedics and can thus provide more comprehensive care to their employees.

In addition to these established lines of patient referral, the Chinese have also institutionalized transfers of personnel between levels. On the one hand, physicians and nurses from the urban hospitals are often 'sent down' to the countryside to teach. do research and disease-prevention work as well as care for patients [32]. On the other hand, paraprofessionals and other health workers from the rural areas periodically receive training or continuing education at county or urban centers. In times of political emphasis on egalitarianism, this movement of personnel was viewed as a major source of education for all involved. Furthermore, these policies reflect the leadership's desire to de-professionalize medicine through the sharing of information with other health 
providers. Very recently, though, there has been a shift away from this egalitarian policy, with emphasis now placed on the modernization of medicine through development of high technologies and urban medical centers [28, 31].

In Yugoslavia, we have seen that direct state involvement in the administration and financing of health care is limited. In contrast, the Chinese state exercises greater control over the administration and some of the financing of health care for its citizens. For example, under the direction of the national Ministry of Health, each provincial Bureau of Health is responsible for the assignment and salary of all staff (with the exception of the rural barefoot doctors and the urban neighborhood paramedics who are selected by their respective brigade or unit and paid through local funds). All job assignments, job descriptions, salary scales and major management and capital investment decisions are made by the state. Private practice was phased out by 1958 [33], although traditional practitioners have been allowed to practice outside the state system [34].

One significant consequence of such centralized planning and administration is the relative lack of autonomy of the physicians vis-à-vis administrators. Physicians are government workers, employed on a fixed salary, with little input into administrative decisions and no other employment options [36]. The technical expertise which brings physicians power within health organizations in other societies [37] is not sufficient to balance the power of administrators who control most other resources. This is particularly true if administrators are also Communist Party members [38]

With regard to financing, the Chinese state assumes responsibility for a substantial portion of health care costs above the rural commune and urban neighborhood and work unit levels. To illustrate, in the provincial level hospital we studied [31], the state paid the health providers' salaries, administrative costs, capital investment above $\$ 7000$, building maintenance and occasional hospital bills which patients could not pay.

Remaining health costs are financed through locallyadministered health insurance funds which, as in Yugoslavia, are organized by occupation. In China, most urban workers and cadres (state-employed professionals and administrators) are fully insured for hospitalization and ordinary outpatient services as part of their employment benefits. On the other hand, rural peasants, temporary workers and workers in some collective enterprises (comprising over $80^{\circ}$ of the total population) finance their health services through local cooperative medical programs which rarely equal the breadth of coverage offered to state employees. Actual coverage for in- and outpatient services varies depending on the wealth of the brigade and commune, or the local enterprise, but was most often quoted to us as $70^{\circ}$, [31].

\section{Gaining access to care}

In a socialist country, particularly one in which a great effort has been made to decentralize delivery, one might expect a minimum of inequities in access to health services. In fact, great strides have been made in this direction in China. However, the organization of care and its financing and the differences in social position of patients continue to be reflected in differential access to care.

Despite vigorous attempts to equalize accessibility. China's rural peasant class remains at a distinct disadvantage. For one thing, the peasant must be referred through more levels than urban dwellers in order to reach comparable health providers. Equally important is the differential hospitalization insurance plan which requires peasants and some workers to pay a portion of the costs. while state workers and cadres are completely covered by their work units. Based on our observations [31]. this appears to affect the peasant's decision to be hospitalized (particularly for chronic illnesses or illness which is inevitably fatal). as well as decisions by hospital clinicians regarding length of stay and medications. Furthermore. the rural patients are more likely to be treated with traditional medicine which remains popular in the countryside and is less expensive than Western-style medicine. Although some traditional procedures have shown themselves quite effective. the value of others has yet to be carefully studied. Peasants are also at a disadvantage with regard to the standard Chinese practice for families to care for relatives in the hospital (i.e. prepare meals, feed them, etc.). Whereas workers and cadres are allowed time off with pay to carry out these nursing tasks. peasants actually lose work points if they choose to care for hospitalized relatives. Finally, the relative disadvantage of the Chinese peasantry is accentuated for those living in less prosperous communes.

Urban workers and cadres, on the other hand. enjoy quicker access to the best medical centers in China. Workers in large factories may be served by primary care clinics with general physicians and specialists before they even reach the hospitals. Workers and cadres are less constrained by hospitalization costs. However, they, like the peasants, are subject to the rules of the bureaucracy and the referral network dictated by membership in their work unit.

One final issue in access is politics. In China's recent past, political activities and history have been a source of differential access to health care, as well as other scarce goods and services. People judge to have 'bad' class backgrounds or performance were denied access to medical care in the more radical phases of the Cultural Revolution. Even today, each urban hospital maintains a special ward for high-level officials and veterans of the 1949 Revolution. Medical care on these wards may not be substantially different, but the physical conditions are superior to those of other wards.

\section{The patient-clinician relationship}

The patient-clinician relationship in China varies with the type of clinician involved. It is worth emphasizing that the existence of more than one type of clinician is, itself, a product of the Chinese sociopolitical context. On the one hand, patients in rural and many urban settings are seen first by a barefoot doctor or paramedic. These health providers are selected from the patient population and continue in their regular jobs as well as perform limited medical duties. Through close contact, patients are thus aware of both their limitations and skills. Furthermore, these 
local paramedics are subject to close supervision by physicians at the commune-level [30].

In contrast, the physician-patient relationship has a different tenor. Physicians did engage in manual labor during the Cultural Revolution alongside their patients, presumably to reduce the differences in status between them. This is no longer the case. Presently, the physician-patient relationship is in fact quite similar to that in Yugoslavia and, indeed, in most societies. According to our observations, patients are rarely given detailed explanations about their illness, the patient compliance is strongly rewarded $[31,36]$. Added to the fact that physicians in China control so few resources which enhance professional power elsewhere (e.g. high prestige, high incomes), this observation suggests that the key variable which leads to such a hierarchical relationship between the clinician and patient is the control of medical information.

The Chinese patient is fairly powerless, but still can marshall other resources when necessary. The patients' families are encouraged to stay with their relatives and are often afforded more information and decision-making power than the patients. If a patient has a specific complaint, a second avenue of redress is through the patient's work unit. A complaint can be lodged with the unit leader who will discuss the problem with the appropriate physician or hospital leader. Not infrequently, the unit leader will take an' active interest in the physician's decisions, and in such situations may have an influence on the patient's care. By so doing, the patient avoids any direct confrontation with the physician which might otherwise be inconsistent with the appropriate sick role. However, this strategy only works to the patient's advantage if the unit leader is genuinely interested in the health care of his/her constituency.

Like their Yugoslav counterparts, then. Chinese patients have developed ways to influence care including the use of relatives and work unit leaders as intermediaries. as well as the use of other "connections' in the health system. According to our observations, though. outright gift-giving occurred in the case of traditional practitioners rather than in the hospital setting [36]. Finally, patients may seek health care outside the designated referral route, but will be reimbursed only if approved by clinic personnel in the work unit. Although these rules reduce doctor shopping by making it an expensive personal maneuver, they leave the patient and his or her unit a variety of health care alternatives.

\section{DISCUSSION}

As largely agrarian and underdeveloped countries. Yugoslavia and China both confronted major problems of development when they emerged as socialist states in the mid-twentieth century. After rejecting the Soviet model of planning and administration. each embarked on its own path to socialism based on its unique interpretation of Marxist ideology and pragmatic considerations. While the Chinese have opted for a highly centralized, state-controlled economy, the Yugoslavs have attempted to reduce the role of centralized state administration and allow a freer play of market forces. However. we might add here that very recent developments in China (e.g. the formation of work councils, experiments with various forms of self-management in industrial enterprises, and incipient forms of private enterprise) show remarkable similarities to the Yugoslav model.

With the common ideological objective to make health care available to all, the two countries have created somewhat different health care systems. In China, a centralized administration coordinates development and integrates the various levels of health care delivery. Apart from medical matters, physicians have relatively little control over the social and economic conditions of their work (e.g. practice sites, salaries). There have been concerted efforts to de-professionalize medicine by sharing information with other health workers and through continued reliance on traditional practitioners. In Yugoslavia, on the other hand, decentralization and self-management have meant somewhat greater autonomy for health workers to control their working conditions (of course, within the boundaries of a socialized health sector). Physicians retain their dominant positions in health institutions, and priority has consistently been given to increasing the supply of these universitytrained health professionals rather than development of paraprofessionals like the Chinese barefoot doctors or Russian feldshers.

Both Yugoslavia and China have made considerable progress relative to their predecessors in improving the accessibility of health care to their respective populations. Yet, neither has succeeded in overcoming inequalities inherited from the pre-revolutionary regimes or associated with priorities set in the course of socialist development. Regardless of the sociopolitical system, tough decisions must be made in allocating scarce (medical) resources. And, in both Yugoslavia and China, these decisions have tended to favor urban industrial workers at the expense of the rural population.

Finally, despite differences in the sociopolitical context and organization of health services, there are nonetheless similarities in the patient-physician relationship. In both countries, the power of the physician vis-à-vis the patient has resisted encroachment. Whether the physician has some autonomy to negotiate the social and economic terms of his/her work (as in Yugoslavia) or occupies a carefully prescribed bureaucratic position (as in China), the relationship between physician and patient is still hierarchical. We would argue that this is due to physicians" continued monopoly on medical information. Nevertheless, patients in each country have devised strategies (e.g. bribes, intermediaries, connections) to exert some measure of control in the medical encounter.

\section{REFERENCES}

1. Bahro R. The Alternatice in Eastern Europe (Translated by Fernbach D.I. NLB, n.p., 1978.

2. Sigerist H. E. Socialized medicine Yale Law Rer. Spring. 39-53, 1938.

3. Navarro $V$. What does Chile mean: an analysis of events in the health sector before. during, and after Allende's administration. Hlth Soc. Milhank Meml. Fund Q. 52. 93-130. 1974.

4. Navarro V. Medicine Lnder Capitalism. Prodist. New York. 1976. 
5. Waitzkin H. B. and Waterman B. The Exploitation of Illness in Capitalist Society: Bobbs-Merrill. Indianapolis, 1974.

6. Rieker P. P. and Begun J. W. Translating social science concepts into medical education: a model and a curriculum. Soc. Sci. Med. 14a. 607-612. 1980.

7. Statistical Yearbook of the SFRY. Federal Statistical Office, Belgrade. 1979.

8. Following Navarro [4], we use the term 'state' to refer to the set of relationships between and among the executive. legislative and judicial branches of government. the administrative bureaucracy, and the army and the police.

9. Schrenk M.. Ardalan C. and El Tatawy N. A. Yuyosiavia: Selfmanagement Socialism and the Challenges of $D^{-}$ velopment. Johns Hopkins University Press. Baltimore. 1979.

10. Sivard R. L. World Military and Social Expenditures 1980. Tables II and III. World Priorities. Leesburg. VA, 1980.

11. Demographic Statistics 1975. Federal Statistical Office Belgrade. 1977.

12. The Public Health Sertice in Yugoslavia. Federal Institute of Public Health. Belgrade. 1975.

13. Statistical Pocket Book of Yurgoslaria. Federal Statistical Office, Belgrade. 1979.

14. Berg R. L., Brooks M. R. Jr and Savičević M. Health Care in Yugoslavia and the United States. Fogarty International Center, Proceedings No. 34, DHEW Publication No. (NIH) 75-911. U.S. Government Printing Office. Washington, DC, 1976

15. U SRH: 302 privatne ordinacije. [In SR Croatia: 302 private clinics.] Vjesnik. Zagreb, 13 June, 1979.

16. Temelj: primarna zdravstvena zaśtita. [The foundation primary health care.] Vjesnik, Zagreb. 30 January, 1980.

17. In addition, some factories or other work organizations also have their own independent health facilities providing some or all outpatient services for their employees.

18. Until recently, separate insurance funds were maintained for these three categories of beneficiaries: i.e workers in the socialized sector, private farmers, and private craft workers and professionals and members of their respective families. Insurance coverage for workers in the socialized sector has generally been more comprehensive than for the other categories. However, there is a trend towards merger of workers and farmers insurance funds and equalization of rights and benefits.

19. The Constitution of the Socialist Federal Republic of Yuqoslavia, Article 186, p. 88, Second (American) English Edition. Cross-Cultural Communications. Merrick, NY, 1976.

20. Unfortunately, precise data on physician earnings in Yugoslavia are unavailable. However, based on positions advertised in a major Zagreb newspaper for the period from October 1977 to March 1980. basic takehome pay ranged between the dinar equivalent of $\$ 400-\$ 800$ per month, depending on the location and type of position (e.g. GP. specialist). This, of course, does not include income which can be earned by being on-call or by moonlighting in a second position. Vor does it include some of the other perquisites offered to attract physicians to the underserved rural areas lapartments, travel expense reimbursement. etc.l.

21. Kunitz S. J. The recruitment. training. and distribution of physicians in Yugoslavia. Int. J. Hith Sert. 10, 593. 1980. Kunitz. however, errs in presenting data for students in all medical sciences (medicine. stomatology, pharmacy) as if they applied to medical students only. Our own research and other data he reports still seem to support the thesis of disproportionate recruitment of physicians from 'middle-class' families.

22. Dernberger R. F. The role of the foreigner in China's economic development. 1840-1949. In China's Modern Economy in Historical Perspective (Edited by Perkins D. H.), p. 19. Stanford University Press. Stanford, 1975.

23. Wegman M. E. Annual summary of vital statistics 1972: with some observations. Pedistrics 52, 881-1973

24. Lampton D. M. Health. Conflict and the Chinese Political Sistem. Michigan Papers in Chinese Studies. Ann Arbor, 1974.

25. Wei Min. 1979: more than 7 million people employed. Beijing Review No. 6, 11 February. 1980.

26. Howe C. China's Economy. Basic Books, New York. 1978

27. Bowers J. Z. Western Medicine in a Chinese Palace: Peking Union College, 1917-1951. Josiah Macy Jr Foundation. New York. 1972.

28. Lampton D. M. Changing health policy in the postMao era. Yale J. Biol. Med. 54, 21-26, 1981.

29. Wu Jieping. The future of postgraduate medical education and training in China. Medical Education in Asia: A Symposium. China Medical Board of New York, Inc., 1981.

30. Lee R. P. L. Chinese and western medical care in China's rural commune: a case study. Soc. Sci. Med. 15A, 137-148, 1981.

31. Henderson G. E. and Cohen M. S. Health care delivery in the People's Republic of China: a view from inside the system. Am. J. publ. Hith. In press.

32. Our Chinese hosts estimated that $10^{\circ}{ }^{\prime}$ of the urban hospital professional staffs could be found in the countryside at any point in time.

33. Whyte M. K. and Parish W. L. Urban Life in Contemporar. China. In press.

34. Very recent reports coming out of China suggest a possible reemergence of legalized private practice [35] as well as more freedom in job assignments of scientists and other professionals [25].

35. Butterfield, $F$. China gingerly gives business a try. The New York Times. E3, 8 March, 1981

36. Henderson G. E. Danwei, the Chinese work unit: a participant-observations study of a hospital. Unpublished doctoral dissertation. Lniversity of Michigan. 1982

37. Freidson E. Professional Dominance. Atherton. New York. 1970.

38. In August 1977, the Eleventh Nationil Congress of the Communist Party of China announced that there were 38 million Communist Party members. or approx. $4^{\prime \prime}$ of the mopulation 